\title{
Greetings from the Editor-in-Chief
}

\author{
Juan Rosellon
}

Published online: 28 January 2014

(C) The Author(s) 2014

Latin American Economic Review (LAER) is an international, refereed open-access journal dedicated to publishing in English original academic research on economics, with rigorous theoretical and methodological standards. In its character of openaccess journal, approved articles will immediately and permanently be available online free of charge for all users. LAER's publication costs are covered by the Centro de Investigación y Docencia Económicas (CIDE, Mexico), which means furthermore that there are no submission fees or article processing charges for authors.

LAER welcomes high-level academic theoretical and empirical research related to Latin American economic problems. However, its scope is not necessarily restricted to this region as long as the proposed research paper deals with issues relevant to the region. Some (illustrative) topics that may be of interest to this journal are: inflation, informal sector, corruption, crime, drug policy, unions, social exclusion, price controls, energy and environmental policy, natural resources, technology transfer, etc.

This journal applies a web-based single-blind review process. Articles are thus refereed by at least two experts in the relevant area. The editors, however, might reject a paper before formal refereeing process if they consider that the paper might not fit within the scope of the journal. The published material should be original, relevant, sound and readable.

We are very proud of having been able to engage in our journal a prominent set of international Associate Editors and Editorial Board members. We would like to thank them as well as the first authors and referees of inaugural papers who have

J. Rosellon $(\bowtie)$

CIDE, Mexico City, Mexico

e-mail: juan.rosellon@ cide.edu

J. Rosellon

DIW, Berlin, Germany 
contributed to a successful start of LAER. We of course also thank the publishing house Springer for its support. We invite everyone to submit further high-quality research manuscripts to make LAER the leading international journal on Latin American economics. 